\title{
Use of Halogen Bonding in a Molecular Solid Solution to Simultaneously Control Spin and Charge
}

\author{
Genta Kawaguchi, ${ }^{* \dagger, \Uparrow}$ Mitsuhiko Maesato, ${ }^{*, \dagger}$ Tokutaro Komatsu, ${ }^{\dagger, \perp}$ Tatsuro Imakubo, ${ }^{*}$ \\ Andhika Kiswandhi, ${ }^{\S, \#}$ David Graf, ${ }^{\S}$ and Hiroshi Kitagawa ${ }^{\dagger}$
}

'Division of Chemistry, Graduate School of Science, Kyoto University, Kitashirakawa-Oiwakecho, Sakyo-ku, Kyoto 606-8502, Japan

${ }^{\ddagger}$ Department of Materials Science and Technology, Nagaoka University of Technology, 1603-1 Kamitomioka, Nagaoka, Niigata 940-2188, Japan

${ }^{\S}$ National High Magnetic Field Laboratory, Florida State University, Tallahassee, Florida 32310, United States

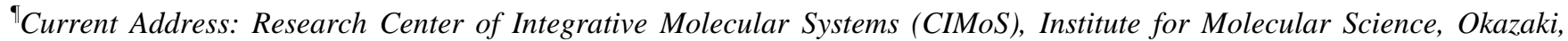
Aichi 444-8585, Japan.

${ }^{\perp}$ Current Address: School of Medicine, Nihon University, Itabashi-ku, Tokyo 173-8610, Japan.

${ }^{\#}$ Current Address: Department of Physics, University of Texas at Dallas, 800 W. Campbell Rd., Richardson, Texas 75080-3021, United States

\section{Contents}

1. Reducing chemical hazards in the synthesis of the selenium-rich compounds $\quad$ S2

2. Elemental analysis by EDX techniques $\quad$ S3

$\begin{array}{ll}\text { 3. Crystal structure analysis } & \text { S4 }\end{array}$

$\begin{array}{ll}\text { 4. Halogen bonds and related structural features } & \text { S7 }\end{array}$

$\begin{array}{ll}\text { 5. Band calculations } & \text { S9 }\end{array}$

6. Effective chemical pressure in (DIETSe) ${ }_{2} \mathrm{MBr}_{4 x} \mathrm{Cl}_{4(1-x)}[\mathrm{M}=\mathrm{Fe}, \mathrm{Ga}] \quad \mathrm{S} 10$

7. Inter-donor distances in (DIETSe) ${ }_{2} \mathrm{MBr}_{4 x} \mathrm{Cl}_{4(1-x)}[\mathrm{M}=\mathrm{Fe}, \mathrm{Ga}] \quad \mathrm{S} 12$

8. Curie-Weiss fitting of (DIETSe) ${ }_{2} \mathrm{FeBr}_{4 x} \mathrm{Cl}_{4(1-x)} \quad$ S13

9. Magnetic torque of (DIETSe) ${ }_{2} \mathrm{FeBr}_{2} \mathrm{Cl}_{2}$ up to $35 \mathrm{~T} \quad \mathrm{~S} 16$

$\begin{array}{ll}\text { 10. Magnetization extrapolation of (DIETSe) }{ }_{2} \mathrm{FeBr}_{4 x} \mathrm{Cl}_{4(1-x)} & \mathrm{S} 17\end{array}$

11. Systematic increase of $\pi-d$ interactions in (DIETSe) ${ }_{2} \mathrm{FeBr}_{4 x} \mathrm{Cl}_{4(1-x)} \quad \mathrm{S} 18$

12. Magnetic torque hysteresis in (DIETSe) ${ }_{2} \mathrm{FeBr}_{4 x} \mathrm{Cl}_{4(1-x)}[x=0.5,0.75] \quad \mathrm{S} 19$

13. Magnetoresistance hysteresis in (DIETSe) ${ }_{2} \mathrm{FeBr}_{4 x} \mathrm{Cl}_{4(1-x)} \quad$ S21

$\begin{array}{ll}\text { Reference } & \text { S23 }\end{array}$ 


\section{Reducing chemical hazards in the synthesis of the selenium-rich compounds}

We have synthesized the selenium-rich $\pi$-donor DIETSe according to a newly developed method, avoiding the use of highly toxic and foul smelling $\mathrm{CSe}_{2}$ or $\mathrm{H}_{2} \mathrm{Se}^{\mathrm{S} 1}$

Indeed, most classical synthetic routes to tetraselenafulvalene (TSF) derivatives require $\mathrm{CSe}_{2}$ or $\mathrm{H}_{2} \mathrm{Se}$, however, our new method utilizes stable and non-volatile selenium powder, which is less toxic and can be handled safely in conventional facilities, as the only source of the selenium in the molecule. The present synthesis of DIETSe could be accomplished with normal care in common chemical laboratories. Chemical reactions, of course, often involve unexpected risks and the work should be performed in a fume hood with safety goggles and gloves.

DIETSe and its cation radical salts are quite stable at ambient condition and require no special additional safety precautions beyond those mentioned above, similar to other TSF derivatives and their cation radical salts. 


\section{Elemental analysis by EDX techniques}

To confirm the composition of $\mathrm{Br}$ and $\mathrm{Cl}$, EDX measurements were performed using a JEOL JSM5510/JED2210 SEM in the Research Center for Low Temperature and Materials Sciences, Kyoto University, Japan. Table S1 and Figure S1 show the average stoichiometry determined from the EDX data, which is consistent with the synthetic ratio.

Table S1. Br/Cl ratio estimated from EDX data

\begin{tabular}{ccc}
\hline Sample & $\begin{array}{c}\text { Synthetic } \\
\text { Br/Cl ratio }\end{array}$ & $\begin{array}{c}\text { Observed } \\
\text { Br/Cl ratio }\end{array}$ \\
\hline \hline (DIETSe $)_{2} \mathrm{FeCl}_{4}$ & $0 / 100$ & $0 / 100$ \\
$(\text { DIETSe })_{2} \mathrm{FeBrCl}_{3}$ & $25 / 75$ & $28(3) / 72(3)$ \\
$(\text { DIETSe })_{2} \mathrm{FeBr}_{2} \mathrm{Cl}_{2}{ }^{\mathrm{S} 2}$ & $50 / 50$ & $51(2) / 49(2)$ \\
$(\text { DIETSe })_{2} \mathrm{FeBr}_{3} \mathrm{Cl}$ & $75 / 25$ & $71(2) / 29(2)$ \\
$(\text { DIETSe})_{2} \mathrm{FeBr}_{4}$ & $100 / 0$ & $100 / 0$ \\
\hline \hline$(\text { DIETSe })_{2} \mathrm{GaCl}_{4}$ & $0 / 100$ & $0 / 100$ \\
$(\text { DIETSe })_{2} \mathrm{GaBrCl}_{3}$ & $25 / 75$ & $30(4) / 70(4)$ \\
$(\mathrm{DIETSe})_{2} \mathrm{GaBr}_{2} \mathrm{Cl}_{2} \mathrm{~S}^{2}$ & $50 / 50$ & $48(2) / 52(2)$ \\
$(\mathrm{DIETSe})_{2} \mathrm{GaBr}_{3} \mathrm{Cl}$ & $75 / 25$ & $72(3) / 28(3)$ \\
$(\mathrm{DIETSe})_{2} \mathrm{GaBr}_{4}$ & $100 / 0$ & $100 / 0$ \\
\hline
\end{tabular}

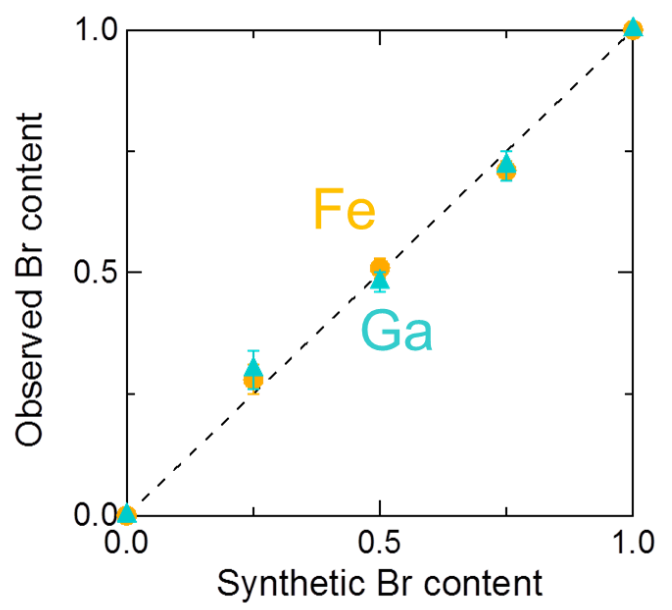

Figure S1. Observed $\mathrm{Br}$ content $x_{\mathrm{obs}}$ plotted versus synthetic one $x_{\mathrm{synth}}$. Dashed line represents the relation, $x_{\mathrm{obs}}=x_{\mathrm{synth}}$. 


\section{Crystal structure analysis}

Tables S2 and S3 summarize the crystallographic data of (DIETSe) ${ }_{2} \mathrm{FeBr}_{4 x} \mathrm{Cl}_{4(1-x)}$ and (DIETSe) ${ }_{2} \mathrm{GaBr}_{4 x} \mathrm{Cl}_{4(1-x)}[x=$ $0,0.25,0.5,0.75,1]$, respectively. Crystallographic data in CIF format have been deposited in the Cambridge Crystallographic Data Centre (CCDC) under deposition numbers indicated in Tables S2 and S3. The previously deposited data of the pristine salts ${ }^{\mathrm{S} 3}$ include slightly different lattice parameters from those shown here, because the diffractometer used is different. The parent salts' CIF files presented with this study are attached as supplemental information.

\section{Specific refinement details}

The residual electron density map suggested two crystallographically independent halide anion $\left(\mathrm{Br}^{-}, \mathrm{Cl}^{-}\right)$sites, which form tetrahedral anion $\left(\mathrm{MBr}_{4 x} \mathrm{Cl}_{4(1-x)}{ }^{-}, x=0,0.25,0.5,0.75,1 ; \mathrm{M}=\mathrm{Fe}, \mathrm{Ga}\right)$ units in the unit cell. Considering the results of the EDX analysis (Table S1), we fixed site occupancies ( $x$ for $\mathrm{Br}$ and $(1-x)$ for $\mathrm{Cl}$ ) and determined the positions of the halide anion species $\left(\mathrm{Br}^{-}, \mathrm{Cl}^{-}\right)$in the refinement process. The site occupancies of the carbon atoms in the ethylene groups (C5A and C5B) were also fixed (0.5 for each). 
Table S2. Crystallographic data of (DIETSe) ${ }_{2} \mathrm{FeBr}_{4 x} \mathrm{Cl}_{4(1-x)}[x=0,0.25,0.5,0.75,1]$

\begin{tabular}{|c|c|c|c|c|c|}
\hline Compounds & $(\mathrm{DIETSe})_{2} \mathrm{FeCl}_{4}$ & $(\text { DIETSe })_{2} \mathrm{FeBrCl}_{3}$ & $(\text { DIETSe })_{2} \mathrm{FeBr}_{2} \mathrm{Cl}_{2}{ }^{\mathrm{S} 2}$ & $(\mathrm{DIETSe})_{2} \mathrm{FeBr}_{3} \mathrm{Cl}$ & $(\mathrm{DIETSe})_{2} \mathrm{FeBr}_{4}$ \\
\hline Formula & $\mathrm{C}_{16} \mathrm{H}_{8} \mathrm{I}_{4} \mathrm{~S}_{4} \mathrm{Se}_{8} \mathrm{FeCl}_{4}$ & $\mathrm{C}_{16} \mathrm{H}_{8} \mathrm{I}_{4} \mathrm{~S}_{4} \mathrm{Se}_{8} \mathrm{FeBrCl}_{3}$ & $\mathrm{C}_{16} \mathrm{H}_{8} \mathrm{I}_{4} \mathrm{~S}_{4} \mathrm{Se}_{8} \mathrm{FeBr}_{2} \mathrm{Cl}_{2}$ & $\mathrm{C}_{16} \mathrm{H}_{8} \mathrm{I}_{4} \mathrm{~S}_{4} \mathrm{Se}_{8} \mathrm{FeBr}_{3} \mathrm{Cl}$ & $\mathrm{C}_{16} \mathrm{H}_{8} \mathrm{I}_{4} \mathrm{~S}_{4} \mathrm{Se}_{8} \mathrm{FeBr}_{4}$ \\
\hline $\begin{array}{l}\text { Formula } \\
\text { weight }\end{array}$ & 1665.39 & 1709.85 & 1754.34 & 1798.77 & 1843.23 \\
\hline Temperature & $293 \mathrm{~K}$ & $293 \mathrm{~K}$ & $293 \mathrm{~K}$ & $293 \mathrm{~K}$ & $293 \mathrm{~K}$ \\
\hline Crystal size & $\begin{array}{l}0.18 \times 0.10 \times 0.01 \\
\mathrm{~mm}^{3}\end{array}$ & $\begin{array}{l}0.14 \\
\mathrm{~mm}^{3}\end{array} \times 0.11 \times 0.02$ & $\begin{array}{l}0.27 \\
\mathrm{~mm}^{3}\end{array} \times 0.08 \times 0.01$ & $\begin{array}{l}0.13 \\
\mathrm{~mm}^{3}\end{array} \times 0.09 \times 0.01$ & $\begin{array}{l}0.16 \times 0.09 \times 0.02 \\
\mathrm{~mm}^{3}\end{array}$ \\
\hline Crystal system & Orthorhombic & Orthorhombic & Orthorhombic & Orthorhombic & Orthorhombic \\
\hline Space group & Ibam (\#72) & Ibam (\#72) & Ibam (\#72) & Ibam (\#72) & Ibam (\#72) \\
\hline$a$ & 7.3315(9) $\AA$ & $7.3346(9) \AA$ & 7.3328(6) $\AA$ & 7.3414(10) ̊ & $7.343(2) \AA$ \\
\hline$b$ & 35.801(4) $\AA$ & $36.110(4) \AA$ & $36.365(3) \AA$ & $36.543(5) \AA$ & $36.610(11) \AA$ \\
\hline$c$ & $13.5837(16) \AA$ & 13.5881(16) $\AA$ & 13.5901(12) $\AA$ & $13.6003(19) \AA$ & 13.592(4) $\AA$ \\
\hline$\alpha$ & $90^{\circ}$ & $90^{\circ}$ & $90^{\circ}$ & $90^{\circ}$ & $90^{\circ}$ \\
\hline$\beta$ & $90^{\circ}$ & $90^{\circ}$ & $90^{\circ}$ & $90^{\circ}$ & $90^{\circ}$ \\
\hline$\gamma$ & $90^{\circ}$ & $90^{\circ}$ & $90^{\circ}$ & $90^{\circ}$ & $90^{\circ}$ \\
\hline$V$ & $3565.4(7) \AA^{3}$ & $3598.9(7) \AA^{3}$ & $3623.9(5) \AA^{3}$ & $3648.6(9) \AA^{3}$ & $3653.7(19) \AA^{3}$ \\
\hline$Z$ & 4 & 4 & 4 & 4 & 4 \\
\hline Density (calcd) & $3.103 \mathrm{~g} / \mathrm{cm}^{3}$ & $3.156 \mathrm{~g} / \mathrm{cm}^{3}$ & $3.215 \mathrm{~g} / \mathrm{cm}^{3}$ & $3.275 \mathrm{~g} / \mathrm{cm}^{3}$ & $3.351 \mathrm{~g} / \mathrm{cm}^{3}$ \\
\hline$F(000)$ & 2984 & 3056 & 3128 & 3200 & 3272 \\
\hline$\mu($ Mo $K \alpha)$ & $12.601 \mathrm{~mm}^{-1}$ & $13.520 \mathrm{~mm}^{-1}$ & $14.465 \mathrm{~mm}^{-1}$ & $15.379 \mathrm{~mm}^{-1}$ & $16.379 \mathrm{~mm}^{-1}$ \\
\hline Abs. correction & Multi-scan & Multi-scan & Multi-scan & Multi-scan & Multi-scan \\
\hline $\begin{array}{l}\text { Reflections } \\
\text { collected }\end{array}$ & 9855 & 9946 & 9844 & 10134 & 10054 \\
\hline $\begin{array}{l}\text { Reflections } \\
\text { unique }\end{array}$ & 2200 & 2255 & 2250 & 2298 & 2276 \\
\hline$R_{\mathrm{int}}$ & 0.0303 & 0.0253 & 0.0403 & 0.0259 & 0.0268 \\
\hline$R_{1}(I>2 \sigma(I))$ & 0.0261 & 0.0225 & 0.0360 & 0.0282 & 0.0303 \\
\hline$w R_{2}$ (all data) & 0.0715 & 0.0636 & 0.0999 & 0.0827 & 0.0810 \\
\hline $\begin{array}{l}\text { Goodness-of-fit } \\
\text { (GOF) }\end{array}$ & 1.077 & 1.052 & 1.119 & 1.085 & 1.039 \\
\hline $\begin{array}{l}\text { Residual } \\
\text { electron } \\
\text { density } \\
\text { max/min }\end{array}$ & $0.641 /-1.003$ e $\AA^{-3}$ & $0.650 /-0.911 \mathrm{e} \AA^{-3}$ & $0.698 /-0.893$ e $\AA^{-3}$ & $0.870 /-0.793$ e $\AA^{-3}$ & $1.516 /-1.348 \mathrm{e} \AA^{-3}$ \\
\hline $\begin{array}{l}\text { CCDC } \\
\text { deposition } \\
\text { number }\end{array}$ & $604643^{\mathrm{S} 3}$ & 1471399 & 1054133 & 1471401 & $604645^{\mathrm{S} 3}$ \\
\hline
\end{tabular}


Table S3. Crystallographic data of (DIETSe) ${ }_{2} \mathrm{GaBr}_{4 x} \mathrm{Cl}_{4(1-x)}[x=0,0.25,0.5,0.75,1]$

\begin{tabular}{|c|c|c|c|c|c|}
\hline Compounds & $(\mathrm{DIETSe})_{2} \mathrm{GaCl}_{4}$ & $(\text { DIETSe })_{2} \mathrm{GaBrCl}_{3}$ & $(\text { DIETSe })_{2} \mathrm{GaBr}_{2} \mathrm{Cl}_{2}{ }^{\mathrm{S} 2}$ & $(\text { DIETSe })_{2} \mathrm{GaBr}_{3} \mathrm{Cl}$ & $(\text { DIETSe })_{2} \mathrm{GaBr}_{4}$ \\
\hline Formula & $\mathrm{C}_{16} \mathrm{H}_{8} \mathrm{I}_{4} \mathrm{~S}_{4} \mathrm{Se}_{8} \mathrm{GaCl}_{4}$ & $\mathrm{C}_{16} \mathrm{H}_{8} \mathrm{I}_{4} \mathrm{~S}_{4} \mathrm{Se}_{8} \mathrm{GaBrCl}_{3}$ & $\mathrm{C}_{16} \mathrm{H}_{8} \mathrm{I}_{4} \mathrm{~S}_{4} \mathrm{Se}_{8} \mathrm{GaBr}_{2} \mathrm{Cl}_{2}$ & $\mathrm{C}_{16} \mathrm{H}_{8} \mathrm{I}_{4} \mathrm{~S}_{4} \mathrm{Se}_{8} \mathrm{GaBr}_{3} \mathrm{Cl}$ & $\mathrm{C}_{16} \mathrm{H}_{8} \mathrm{I}_{4} \mathrm{~S}_{4} \mathrm{Se}_{8} \mathrm{GaBr}_{4}$ \\
\hline $\begin{array}{l}\text { Formula } \\
\text { weight }\end{array}$ & 1679.26 & 1723.72 & 1768.18 & 1812.64 & 1857.10 \\
\hline Temperature & $293 \mathrm{~K}$ & $293 \mathrm{~K}$ & $293 \mathrm{~K}$ & $293 \mathrm{~K}$ & $293 \mathrm{~K}$ \\
\hline Crystal size & $\begin{array}{l}0.13 \times 0.11 \times 0.01 \\
\mathrm{~mm}^{3}\end{array}$ & $\begin{array}{l}0.12 \\
\mathrm{~mm}^{3}\end{array} \times 0.11 \times 0.02$ & $\begin{array}{l}0.18 \times 0.16 \times 0.02 \\
\mathrm{~mm}^{3}\end{array}$ & $\begin{array}{l}0.13 \\
\mathrm{~mm}^{3}\end{array} \times 0.12 \times 0.01$ & $\begin{array}{l}0.16 \times 0.06 \times 0.01 \\
\mathrm{~mm}^{3}\end{array}$ \\
\hline Crystal system & Orthorhombic & Orthorhombic & Orthorhombic & Orthorhombic & Orthorhombic \\
\hline Space group & Ibam (\#72) & Ibam (\#72) & Ibam (\#72) & Ibam (\#72) & Ibam (\#72) \\
\hline$a$ & 7.339(2) $\AA$ & 7.341(2) $\AA$ & 7.3400(7) $\AA$ & $7.3476(12) \AA$ & $7.3519(13) \AA$ \\
\hline$b$ & $35.846(11) \AA$ & $36.180(10) \AA$ & $36.3615(3) \AA$ & $36.592(6) \AA$ & $36.690(6) \AA$ \\
\hline$c$ & 13.576(4) $\AA$ & $13.586(4) \AA$ & $13.5970(13) \AA$ & 13.602(2) $\AA$ & 13.606(2) $\AA$ \\
\hline$\alpha$ & $90^{\circ}$ & $90^{\circ}$ & $90^{\circ}$ & $90^{\circ}$ & $90^{\circ}$ \\
\hline$\beta$ & $90^{\circ}$ & $90^{\circ}$ & $90^{\circ}$ & $90^{\circ}$ & $90^{\circ}$ \\
\hline$\gamma$ & $90^{\circ}$ & $90^{\circ}$ & $90^{\circ}$ & $90^{\circ}$ & $90^{\circ}$ \\
\hline$V$ & $3571.4(19) \AA^{3}$ & $3608.5(17) \AA^{3}$ & $3628.9(6) \AA^{3}$ & $3657.1(10) \AA^{3}$ & $3670.2(11) \AA^{3}$ \\
\hline$Z$ & 4 & 4 & 4 & 4 & 4 \\
\hline Density (calcd) & $3.123 \mathrm{~g} / \mathrm{cm}^{3}$ & $3.173 \mathrm{~g} / \mathrm{cm}^{3}$ & $3.236 \mathrm{~g} / \mathrm{cm}^{3}$ & $3.292 \mathrm{~g} / \mathrm{cm}^{3}$ & $3.361 \mathrm{~g} / \mathrm{cm}^{3}$ \\
\hline$F(000)$ & 3004 & 3076 & 3148 & 3220 & 3292 \\
\hline$\mu($ Mo $K \alpha)$ & $12.928 \mathrm{~mm}^{-1}$ & $13.828 \mathrm{~mm}^{-1}$ & $14.787 \mathrm{~mm}^{-1}$ & $15.684 \mathrm{~mm}^{-1}$ & $16.644 \mathrm{~mm}^{-1}$ \\
\hline Abs. correction & Multi-scan & Multi-scan & Multi-scan & Multi-scan & Multi-scan \\
\hline $\begin{array}{l}\text { Reflections } \\
\text { collected }\end{array}$ & 9856 & 9995 & 9817 & 10119 & 10130 \\
\hline $\begin{array}{l}\text { Reflections } \\
\text { unique }\end{array}$ & 2248 & 2270 & 2244 & 2298 & 2295 \\
\hline$R_{\mathrm{int}}$ & 0.0273 & 0.0297 & 0.0351 & 0.0285 & 0.0243 \\
\hline$R_{1}(I>2 \sigma(I))$ & 0.0266 & 0.0272 & 0.0246 & 0.0310 & 0.0297 \\
\hline$w R_{2}$ (all data) & 0.0778 & 0.0874 & 0.0762 & 0.0915 & 0.0760 \\
\hline $\begin{array}{l}\text { Goodness-of-fit } \\
\text { (GOF) }\end{array}$ & 1.040 & 1.024 & 1.106 & 1.041 & 1.038 \\
\hline $\begin{array}{l}\text { Residual } \\
\text { electron } \\
\text { density } \\
\text { max/min }\end{array}$ & $0.687 /-0.584 \mathrm{e} \AA^{-3}$ & $1.041 /-0.476 \mathrm{e} \AA^{-3}$ & $0.564 /-0.670 \mathrm{e} \AA^{-3}$ & $0.914 /-0.750$ e $\AA^{-3}$ & $1.548 /-1.443 \mathrm{e} \AA^{-3}$ \\
\hline $\begin{array}{l}\text { CCDC } \\
\text { deposition } \\
\text { number }\end{array}$ & $604644^{\mathrm{S3}}$ & 1471400 & 1054132 & 1471402 & $604646^{53}$ \\
\hline
\end{tabular}




\section{Halogen bonds and related structural features}

Bond lengths of the halogen bonds of (DIETSe) ${ }_{2} \mathrm{MX}_{4}[\mathrm{M}=\mathrm{Fe}, \mathrm{Ga} ; \mathrm{X}=\mathrm{Br}, \mathrm{Cl}]$ are shown in Table S4, where $d(\mathrm{I}-$ $\mathrm{X})$ and $d(\mathrm{I}-\mathrm{S})$ denote inter-atomic distances as shown in Figures S2. The value in bracket represents the relative inter-atomic distance compared with the sum of the van der Waals radii. ${ }^{S 4}$ For example, $[-5.6 \%]$ means the observed distance is $5.6 \%$ shorter than the sum of van der Waals radii.

Table S4. Bond lengths of halogen bonds of (DIETSe) ${ }_{2} \mathrm{MX}_{4}[\mathrm{M}=\mathrm{Fe}, \mathrm{Ga} ; \mathrm{X}=\mathrm{Br}, \mathrm{Cl}]$ (see also Figures S2)

\begin{tabular}{ccc|cc}
\hline & $\mathrm{GaCl}_{4}$ & $\mathrm{GaBr}_{4}$ & $\mathrm{FeCl}_{4}$ & $\mathrm{FeBr}_{4}$ \\
\hline \hline \multirow{2}{*}{$d(\mathrm{I}-\mathrm{X})$} & $3.520 \AA$ & $3.639 \AA$ & $3.500 \AA$ & $3.622 \AA$ \\
& {$[-5.6 \%]$} & {$[-5.0 \%]$} & {$[-6.2 \%]$} & {$[-5.4 \%]$} \\
$d(\mathrm{I}-\mathrm{S})$ & $3.639 \AA$ & $3.634 \AA$ & $3.634 \AA$ & $3.623 \AA$ \\
& {$[-3.7 \%]$} & {$[-3.9 \%]$} & {$[-3.9 \%]$} & {$[-4.2 \%]$} \\
\hline
\end{tabular}

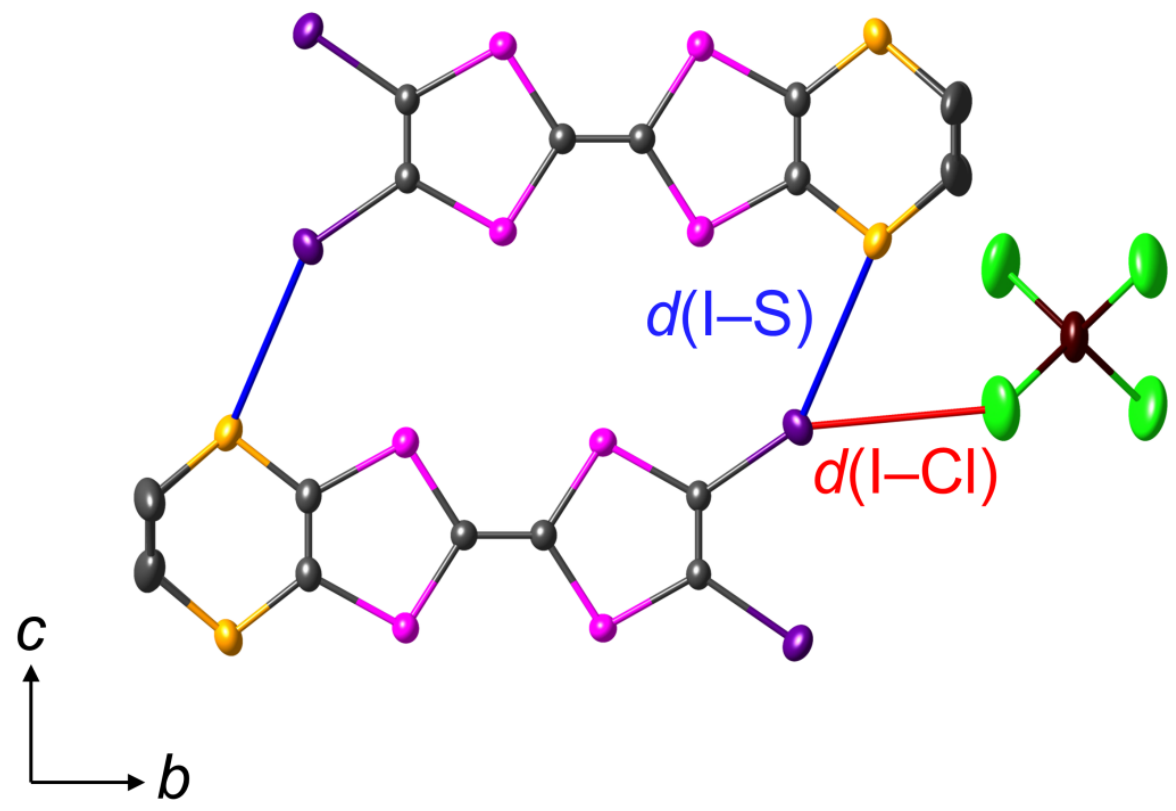

Figure S2. Halogen bonds in the $\mathrm{FeCl}_{4}$ salt. Red and blue lines indicate $\mathrm{I}-\mathrm{X}[\mathrm{X}=\mathrm{Br}, \mathrm{Cl}]$ and $\mathrm{I}-\mathrm{S}$ halogen bonds, which are donor-anion-type and inter-donor-type, respectively. 
We also note the short halogen-halogen distances between neighboring anions along the $c$ and $a$ axes are more than $13 \%$ and $40 \%$ longer than the sum of van der Waals radii, respectively (Figure S3a), indicating ineffective inter-anion interactions for magnetism.

It is interesting to note that $\mathrm{I}-\mathrm{X}$ halogen bonds cause the distortions of tetrahedron anions (Figures S3b and S3c). There are three kinds of bonding angles of anion tetrahedron. One of them (colored blue in Figure S3b) is significantly smaller than regular tetrahedron bond angle $\left(\sim 109.5^{\circ}\right)$, indicating elongated tetrahedron along the $a$ axis (Figure S3b). In the $b c$ plane, a slight compression along the $c$ axis is observed (Figure S3c). These bond angles are almost unchanged by halogen substitution. Considering weak inter-anion interactions, these discrepancies from regular tetrahedron are attributed to strong $\mathrm{I}-\mathrm{X}$ halogen bonds.
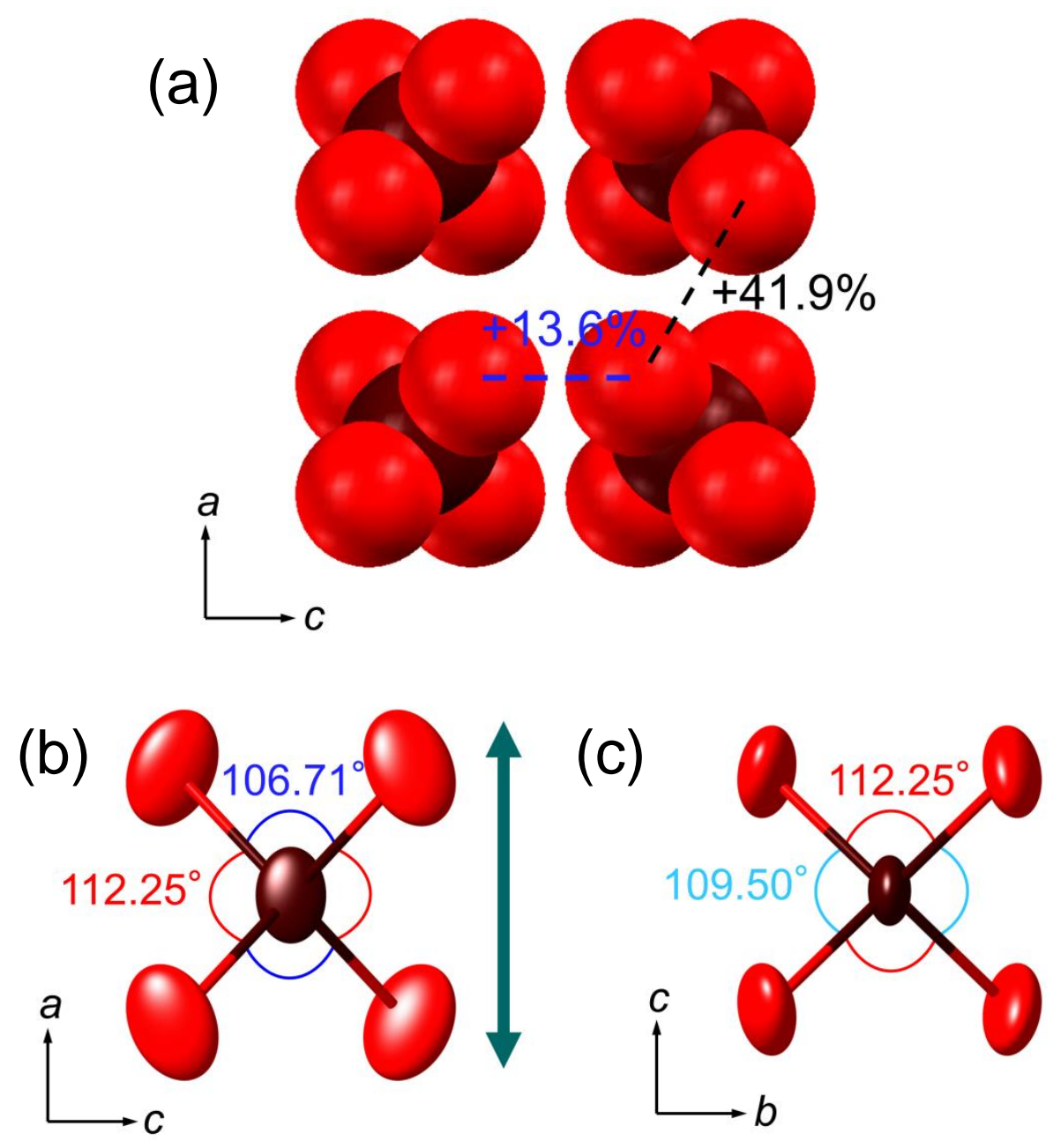

Figure S3. (a) Short halogen-halogen distances between neighboring anions along the $c$ and $a$ axes in (DIETSe) ${ }_{2} \mathrm{FeBr}_{4}$. Bonding angles of $\mathrm{FeBr}_{4}{ }^{-}$anion in (DIETSe) ${ }_{2} \mathrm{FeBr}_{4}$ in the $a c$ plane (b) and the $b c$ plane (c). 


\section{Band calculations}

Band calculations were carried out using density functional theory (PBE functional ${ }^{\mathrm{S} 5}$ ) implemented in $\mathrm{CASTEP}^{\mathrm{S} 6}$ in Materials Studio (Accelrys Software Inc.). Plane-wave basis functions with a cutoff energy of $330 \mathrm{eV}$ were used with ultrasoft pseudopotentials. ${ }^{S 7}$ The hydrogen atoms of the ethylene groups in the $\mathrm{MBr}_{4 x} \mathrm{Cl}_{4(1-x)}[\mathrm{M}=\mathrm{Fe}, \mathrm{Ga}]$ salts were attached assuming a $\mathrm{C}-\mathrm{H}$ bond distance of $1.07 \AA$ and $\mathrm{sp}^{3}$ hybridization. The reported crystal structures ${ }^{\mathrm{S}}$ were used for the pristine compounds. To eliminate the disorder in the ethylene groups, the symmetry of the crystal was lowered from Ibam (D2h) to I2/b (C2h), Pbcn (D2h), Pccn (D2h), and I222 (D2). The relative energies in the case of the $\mathrm{GaCl}_{4}$ salt were $1.8,0.0,4.4$, and $2.0 \mathrm{meV}$, respectively. The Fermi surfaces were obtained for the lowest energy conformation, Pbcn. The calculated Fermi surfaces of the $\mathrm{MBr}_{4 x} \mathrm{Cl}_{4(1-x)}[\mathrm{M}=\mathrm{Fe}, \mathrm{Ga}]$ salts are almost identical (Figure S4), with a Fermi pocket whose area is $9-10 \%$ of the first Brillouin zone (FBZ). Even though the Fermi surfaces of the pristine salts calculated using the extended Hückel method ${ }^{\mathrm{S} 8}$ indicated a pocket with an area of ca. $5 \%$ of the FBZ, ${ }^{\mathrm{S} 3}$ we observed quantum oscillations in magnetoresistance corresponding to an area of about $10 \%$ in some of the pristine and mixed salts, ${ }^{S 9}$ supporting the DFT calculations.
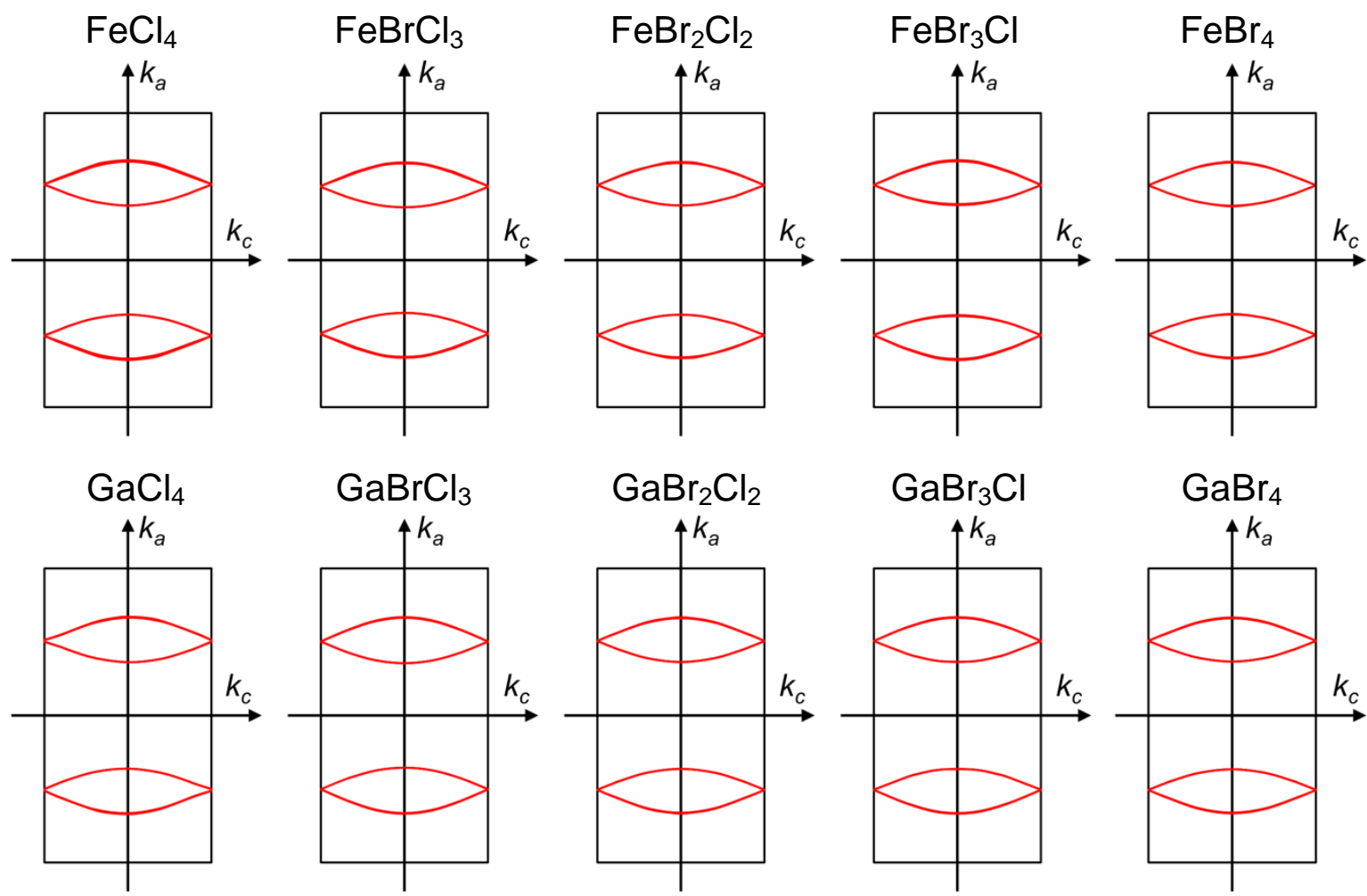

Figure S4. Fermi surfaces of (DIETSe) ${ }_{2} \mathrm{MBr}_{4 x} \mathrm{Cl}_{4(1-x)}[\mathrm{M}=\mathrm{Fe}, \mathrm{Ga}$ by DFT. Similar Q1D Fermi surfaces are predicted for any halogen ratio. 
6. Effective chemical pressure in (DIETSe) ${ }_{2} \mathrm{MBr}_{4 x} \mathrm{Cl}_{4(1-x)}[\mathrm{M}=\mathrm{Fe}, \mathrm{Ga}]$

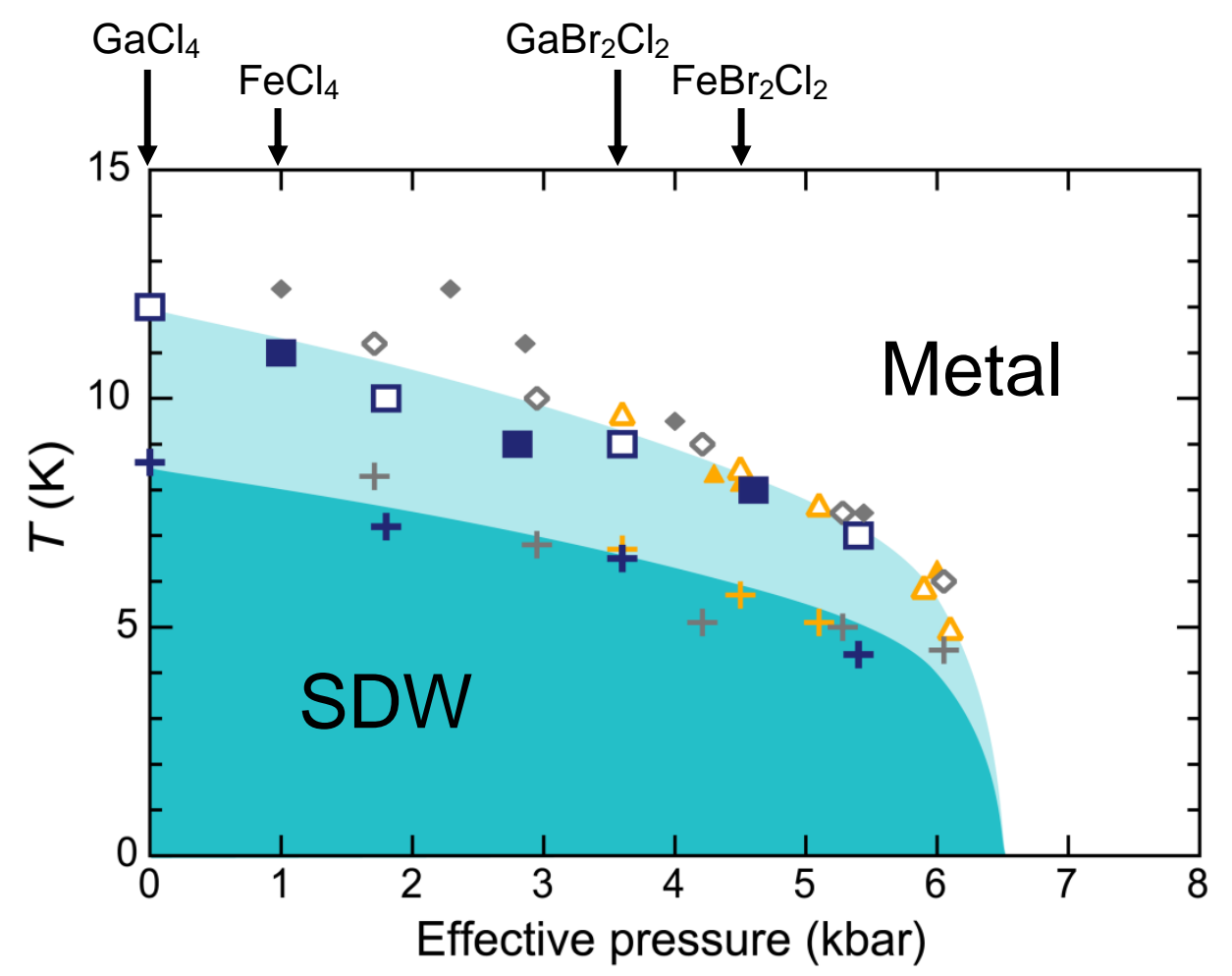

SDW onset

$\square$ Solid solution (DIETSe) ${ }_{2} \mathrm{GaBr}_{4 x} \mathrm{Cl}_{4(1-x)}$

- Solid solution (DIETSe) ${ }_{2} \mathrm{FeBr}_{4 x} \mathrm{Cl}_{4(1-x)}$

$\diamond \quad(\mathrm{DIETSe})_{2} \mathrm{GaCl}_{4}$ under pressure ${ }^{\mathrm{S} 10}$

- (DIETSe) ${ }_{2} \mathrm{FeCl}_{4}$ under pressure ${ }^{\mathrm{S} 10}$

$\triangle$ (DIETSe) $)_{2} \mathrm{GaBr}_{2} \mathrm{Cl}_{2}$ under pressure ${ }^{\mathrm{S} 11}$

$\triangle \quad(\text { DIETSe })_{2} \mathrm{FeBr}_{2} \mathrm{Cl}_{2}$ under pressure ${ }^{\mathrm{S} 11}$

SDW long-range order (LRO)

$+\quad$ Solid solution (DIETSe) ${ }_{2} \mathrm{GaBr}_{4 x} \mathrm{Cl}_{4(1-x)}$

$+\quad(\mathrm{DIETSe})_{2} \mathrm{GaCl}_{4}$ under pressure ${ }^{\mathrm{S} 10}$

+ (DIETSe) $)_{2} \mathrm{GaBr}_{2} \mathrm{Cl}_{2}$ under pressure ${ }^{\mathrm{S} 11}$

Figure S5. Effective chemical pressure relative to the most low-dimensional (DIETSe) ${ }_{2} \mathrm{GaCl}_{4}$. The temperature- $\mathrm{Br}$ content $(T-x)$ phase diagrams and the temperature-pressure $(T-P)$ phase diagrams we previously reported ${ }^{\mathrm{S} 10, \mathrm{~S} 11}$ are collapsed into the identical phase diagram from onset and long-range order (LRO) temperatures of SDW, assuming chemical pressure is proportional to $\mathrm{Br}$ content $x$. SDW onset and LRO temperatures were defined by the minimum of resistivity $\rho$ and the peak in $d\{\ln (\rho)\} / d(1 / T)$, respectively. We estimated chemical pressure relative to (DIETSe) ${ }_{2} \mathrm{MCl}_{4}$ $[\mathrm{M}=\mathrm{Fe}, \mathrm{Ga}], P_{\text {chem }} / \operatorname{kbar} \sim 7.2 x$, where $x$ denotes $\mathrm{Br}$ content and $0<x<1$. We note that the Fe salt has 1 kbar higher chemical pressure than the equivalent $\mathrm{Ga}$ salt. These results demonstrate that $\mathrm{Br}$ substitution enhances the 
dimensionality of $\pi$ electrons to suppress the SDW ground state in a similar manner as physical pressure. 
7. Inter-donor distances in (DIETSe) ${ }_{2} \mathrm{MBr}_{4 x} \mathrm{Cl}_{4(1-x)}[\mathrm{M}=\mathrm{Fe}, \mathrm{Ga}]$

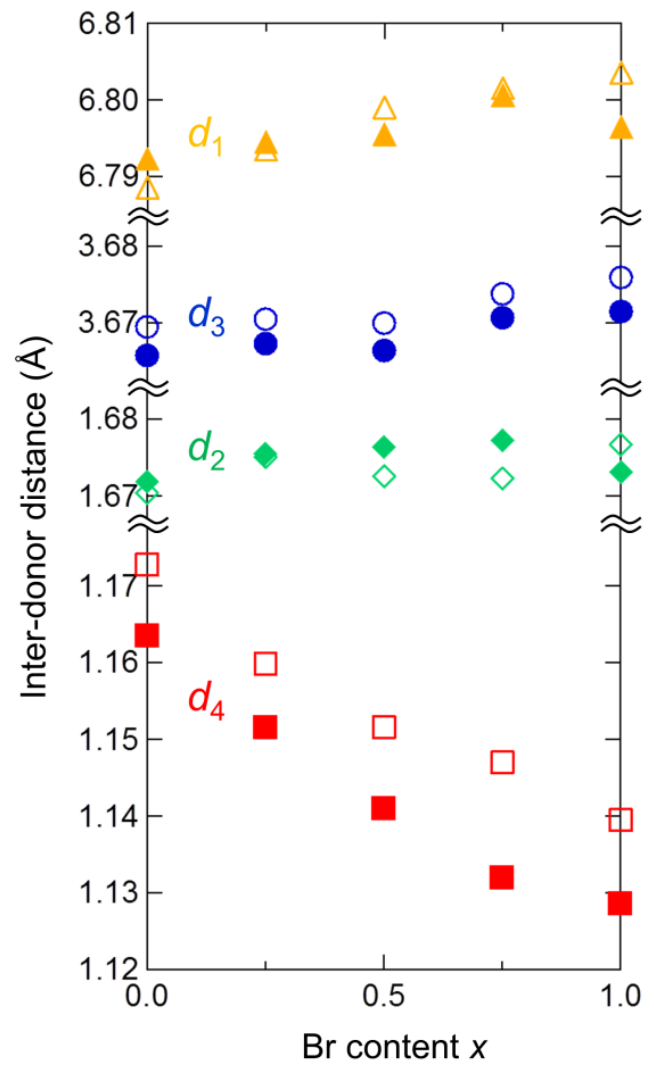

Figure S6. Absolute values of inter-donor distances $d_{1}, d_{2}, d_{3}$, and $d_{4}$ (see Figures $3 \mathrm{a}$ and $3 \mathrm{~b}$ ). Open and closed symbols denote the values for the $\mathrm{Ga}$ and $\mathrm{Fe}$ species, respectively. $d_{4}$, which is associated with side-by-side interactions of one-dimensional columns, is larger in the Ga species than the Fe species. This difference in $d_{4}$ results in relatively lower dimensionality of $\pi$ electrons in the Ga salt than the Fe salt (see Figure S5 and description). 


\section{Curie-Weiss fitting of (DIETSe) ${ }_{2} \mathrm{FeBr}_{4 x} \mathrm{Cl}_{4(1-x)}$}

Temperature dependences of the magnetic susceptibilities of the $\mathrm{FeCl}_{4}, \mathrm{FeBrCl}_{3}, \mathrm{FeBr}_{2} \mathrm{Cl}_{2}, \mathrm{FeBr}_{3} \mathrm{Cl}$, and $\mathrm{FeBr}_{4}$ salts are shown in Figures S7, S8, S9, S10, and S11, respectively. The inset shows the low-temperature region. The core diamagnetic susceptibility is already subtracted. The black line indicates the Curie-Weiss fitting, where the obtained Curie constant $C$, Weiss temperature $\theta$, and fitting temperature range are represented in the Figure. $C$ is consistent with $\mathrm{Fe}^{3+}$ spins $(S=5 / 2, C=4.4 \mathrm{emu} \mathrm{K} / \mathrm{mol})$. Figure $\mathrm{S} 12$ shows $|\theta|$ plotted versus Br content $x$.

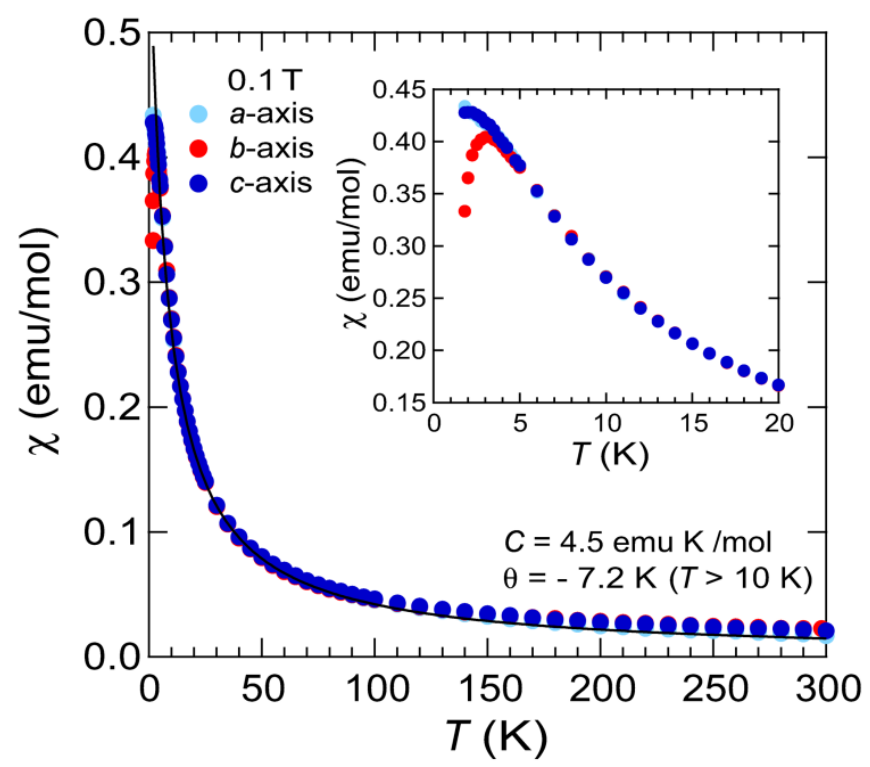

Figure S7. Temperature dependence of the magnetic susceptibility of (DIETSe) ${ }_{2} \mathrm{FeCl}_{4}$ at $0.1 \mathrm{~T}^{\mathrm{S} 3}$

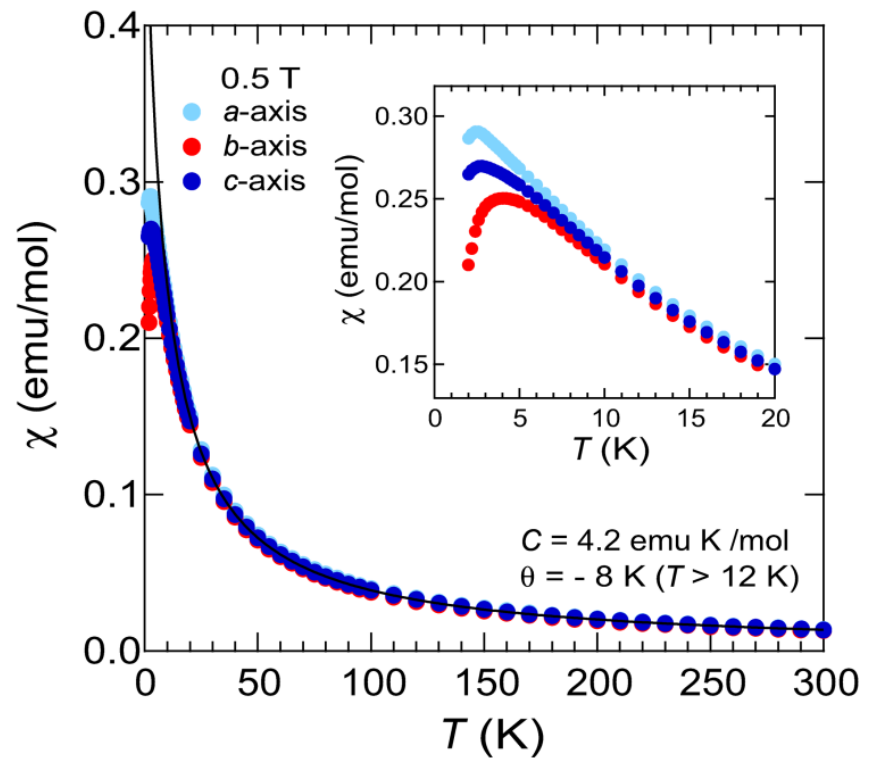

Figure S8. Temperature dependence of the magnetic susceptibility of (DIETSe) ${ }_{2} \mathrm{FeBrCl}_{3}$ at $0.5 \mathrm{~T}$. 


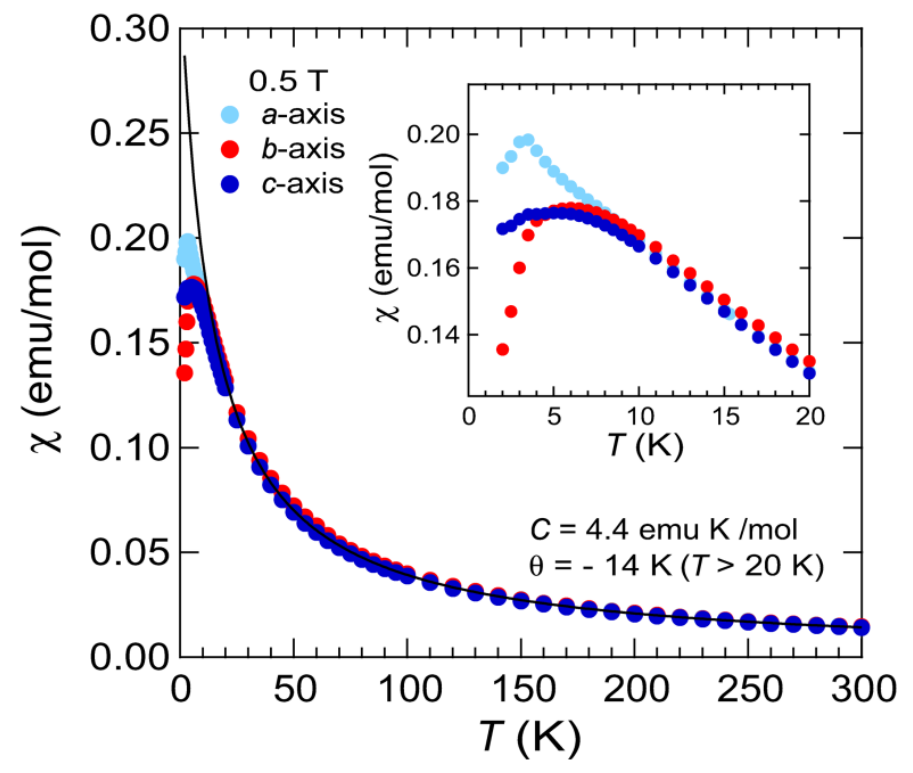

Figure S9. Temperature dependence of the magnetic susceptibility of (DIETSe) ${ }_{2} \mathrm{FeBr}_{2} \mathrm{Cl}_{2}$ at $0.5 \mathrm{~T} .{ }^{\mathrm{S} 2}$

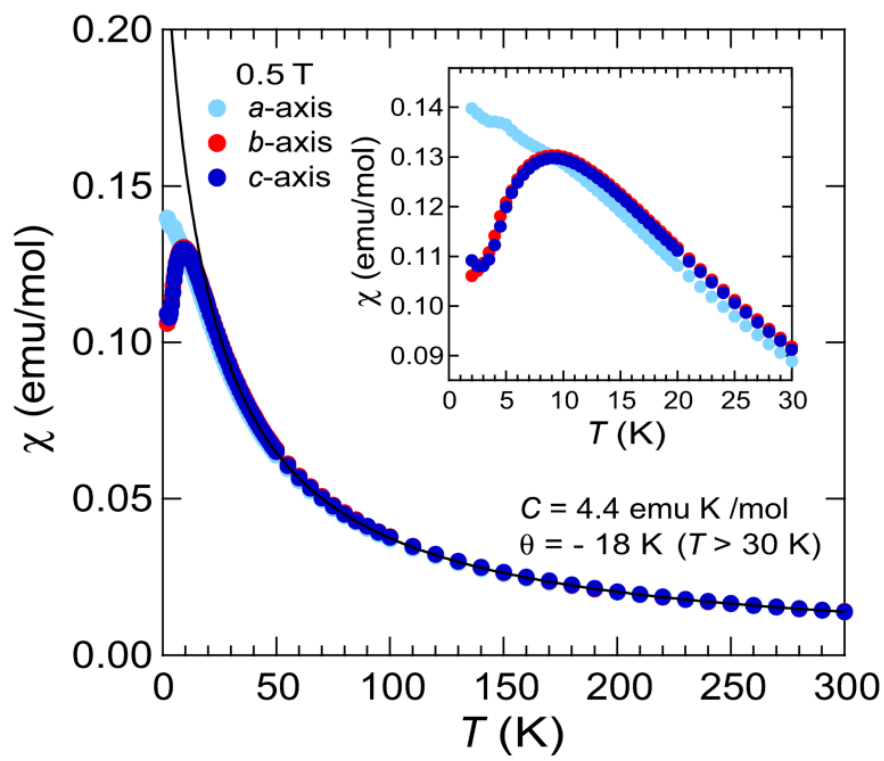

Figure S10. Temperature dependence of the magnetic susceptibility of (DIETSe) ${ }_{2} \mathrm{FeBr}_{3} \mathrm{Cl}$ at $0.5 \mathrm{~T}$. 


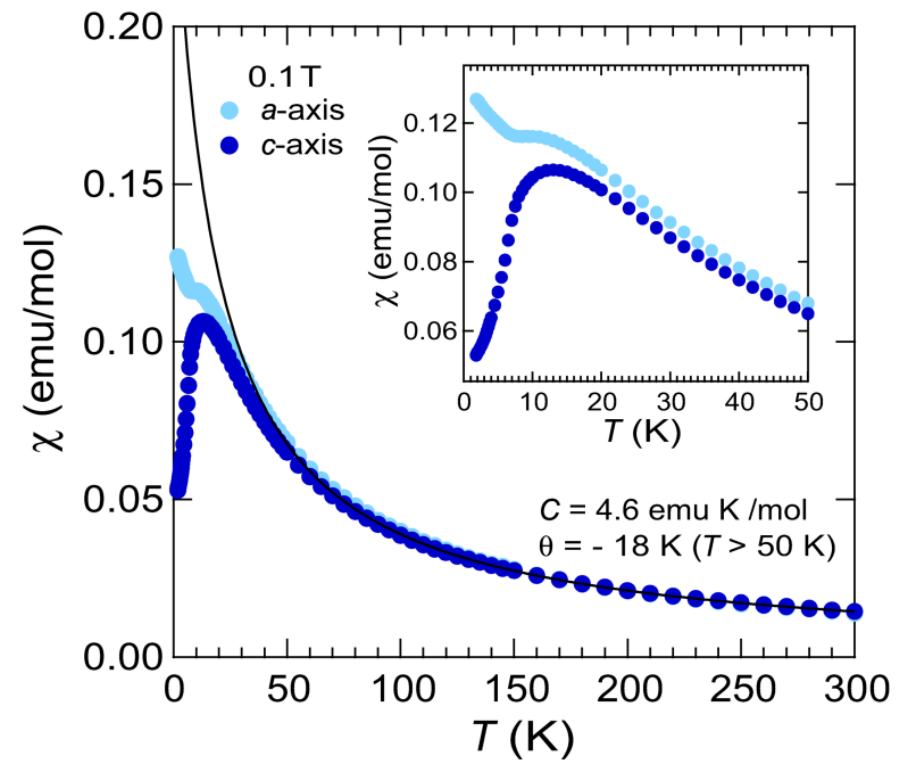

Figure S11. Temperature dependence of the magnetic susceptibility of (DIETSe) ${ }_{2} \mathrm{FeBr}_{4}$ at $0.1 \mathrm{~T}^{\mathrm{S} 3}$

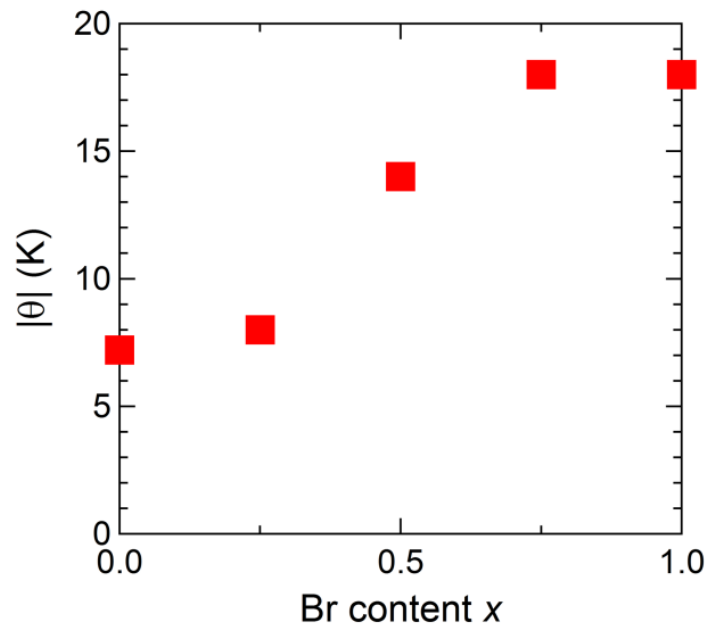

Figure S12. Absolute value of Weiss temperature $|\theta|$ of (DIETSe) ${ }_{2} \mathrm{FeBr}_{4 x} \mathrm{Cl}_{4(1-x)}$. $|\theta|$ increases with increasing $\mathrm{Br}$ content $x$, suggesting the reinforcement of $\pi-d$ interactions. 
9. Magnetic torque of (DIETSe) ${ }_{2} \mathrm{FeBr}_{2} \mathrm{Cl}_{2}$ up to $35 \mathrm{~T}$

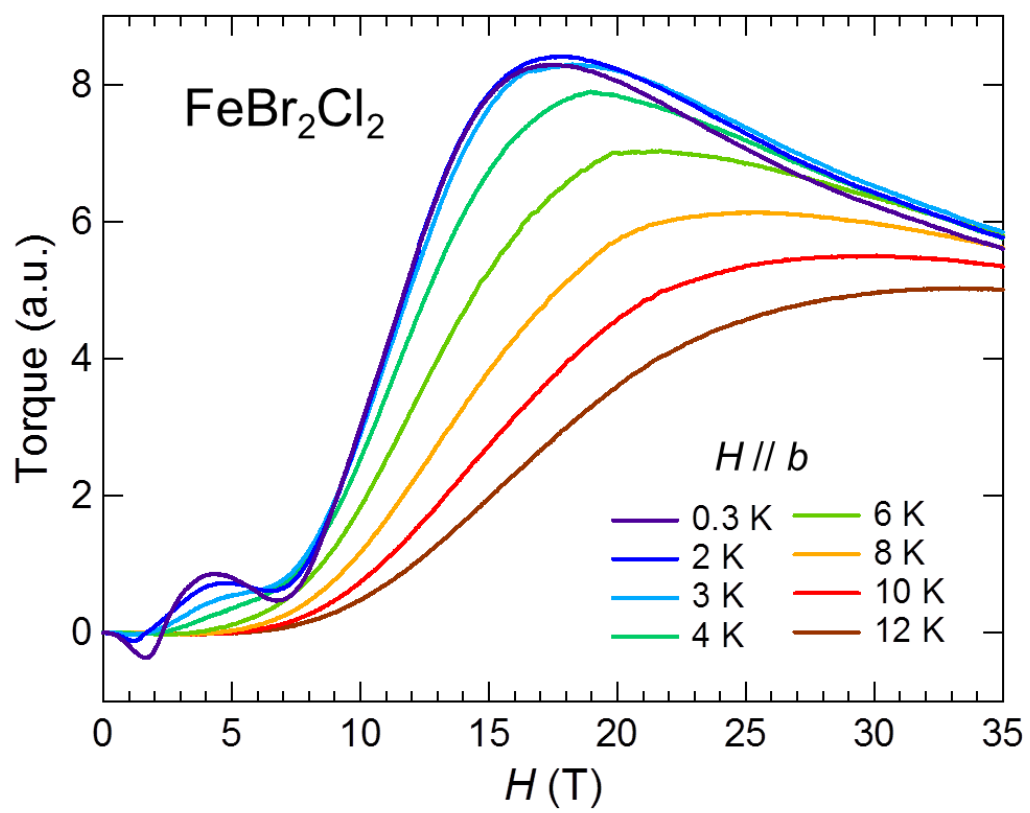

Figure S13. Magnetic torque of the $\mathrm{FeBr}_{2} \mathrm{Cl}_{2}$ salt up to $35 \mathrm{~T}$. Magnetic field is applied along the $b$ axis. 
10. Magnetization extrapolation of (DIETSe) ${ }_{2} \mathrm{FeBr}_{4 x} \mathrm{Cl}_{4(1-x)}$

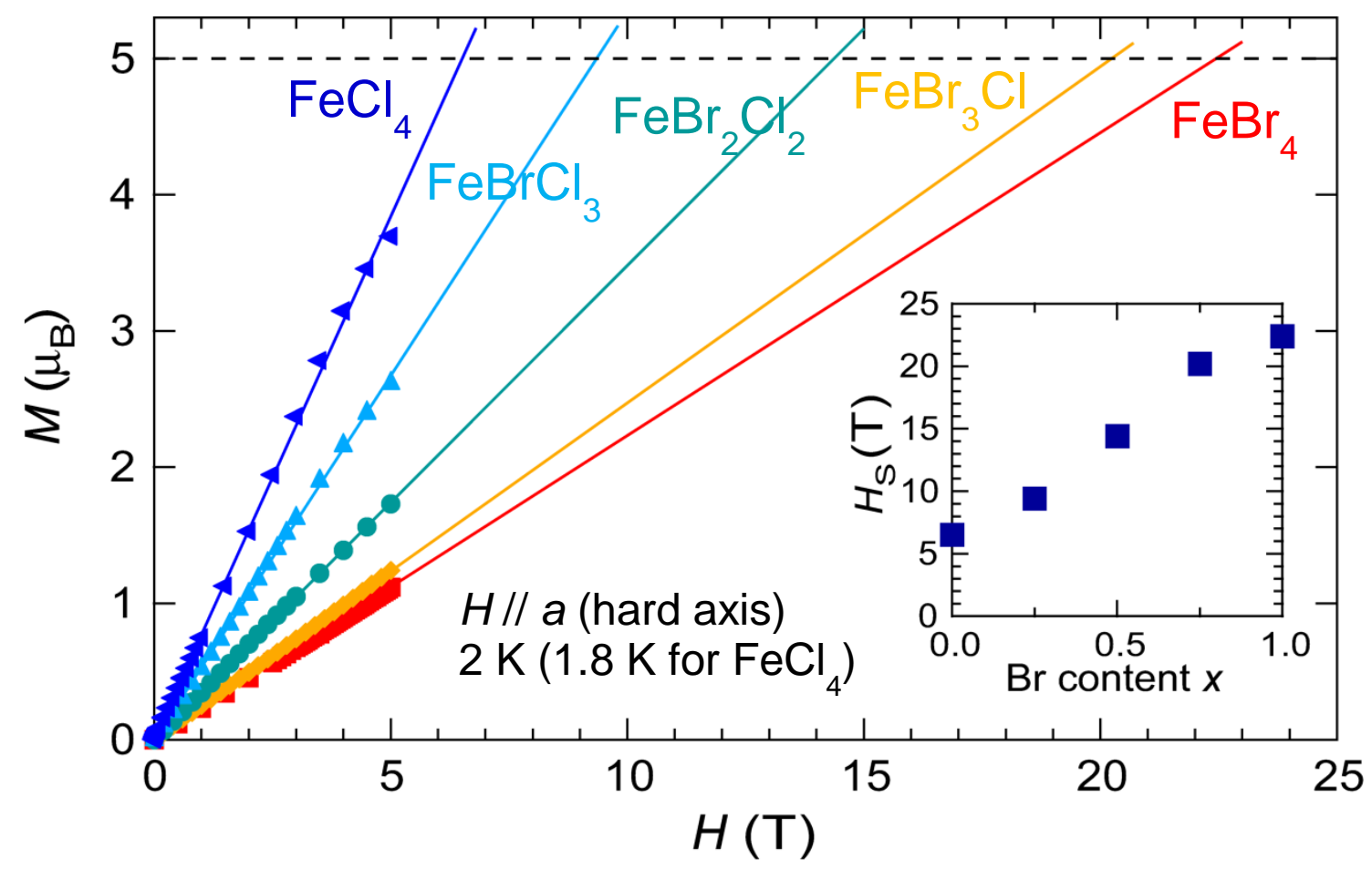

Figure S14. Magnetization $M$ of the $\mathrm{FeCl}_{4}, \mathrm{FeBrCl}_{3}, \mathrm{FeBr}_{2} \mathrm{Cl}_{2}, \mathrm{FeBr}_{3} \mathrm{Cl}$, and $\mathrm{FeBr}_{4}$ salts, where the magnetic field is applied along the $a$ axis, corresponding to the hard axis. Solid line shows the linear extrapolation, whose crossing point with dashed line, $M=5 \mu_{\mathrm{B}}$, gives an estimated saturation field $H_{\mathrm{S}}$. Inset indicates $H_{\mathrm{S}}$ plotted against $\mathrm{Br}$ content $x$. An almost linear relationship between $H_{\mathrm{S}}$ and $x$ is observed, suggesting the enhancement of $\pi-d$ interactions. 
11. Systematic increase of $\pi-d$ interactions in (DIETSe) $)_{2} \mathrm{FeBr}_{4 x} \mathrm{Cl}_{4(1-x)}$

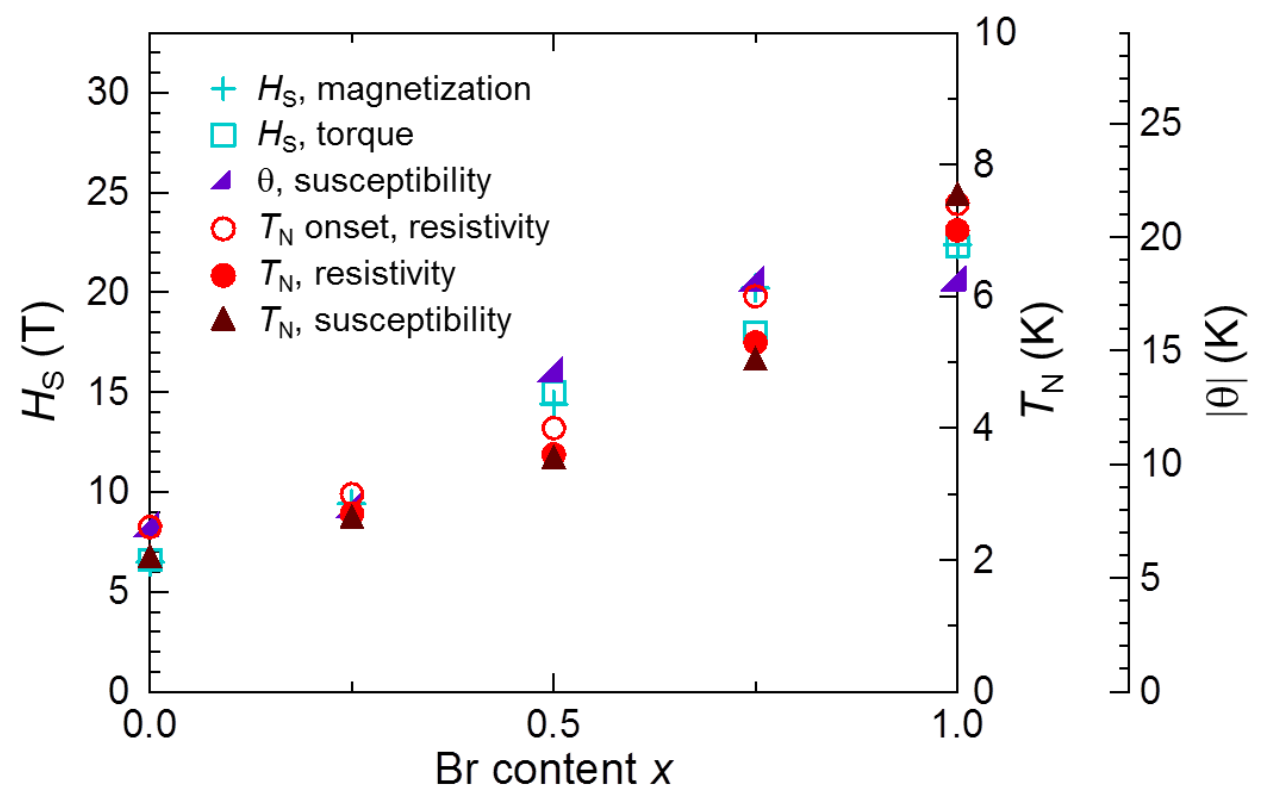

Figure S15. Saturation field $H_{\mathrm{S}}$, Weiss temperature $|\theta|$, Néel temperature $T_{\mathrm{N}}$ plotted against $\mathrm{Br}$ content $x . H_{\mathrm{S}},|\theta|$, and $T_{\mathrm{N}}$ have linear relationships with $x$, suggesting systematic increases of $\pi-d$ interactions. 
12. Magnetic torque hysteresis in (DIETSe) ${ }_{2} \mathrm{FeBr}_{4 x} \mathrm{Cl}_{4(1-x)}[x=0.5,0.75]$

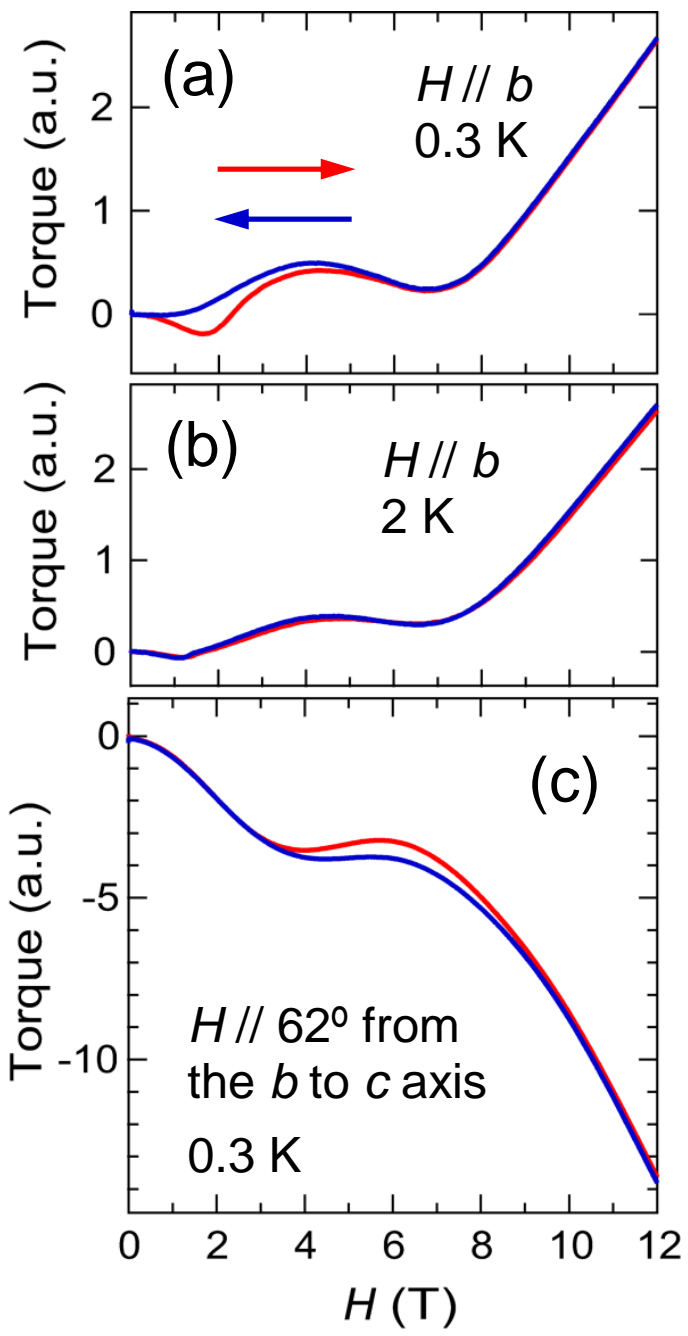

Figure S16. Hysteresis of the magnetic torque of the $\mathrm{FeBr}_{2} \mathrm{Cl}_{2}$ salt. Red and blue curves indicate up and down sweep, respectively. (a) Torque at $0.3 \mathrm{~K}$ under the field along the $b$ axis. (b) Torque at $2 \mathrm{~K}$ under the field along the $b$ axis. (c) Torque at $0.3 \mathrm{~K}$ under the field along $62^{\circ}$ from the $b$ to $c$ axis. Torque hysteresis is not obvious at $2 \mathrm{~K}$, in contrast to significant hysteresis at $0.3 \mathrm{~K}$, suggesting a metastable nature of the hysteresis. When the field is applied along the $b$ axis near the easy axis, hysteresis is pronounced at the spin-flop transition, as shown in (a). Meanwhile, when the field direction is away from easy axis, hysteresis becomes large around the AF-PM boundary, as shown in (c). These features are also observed in the $\mathrm{FeBr}_{3} \mathrm{Cl}$ salt (Figure $\mathrm{S} 17$ ). 


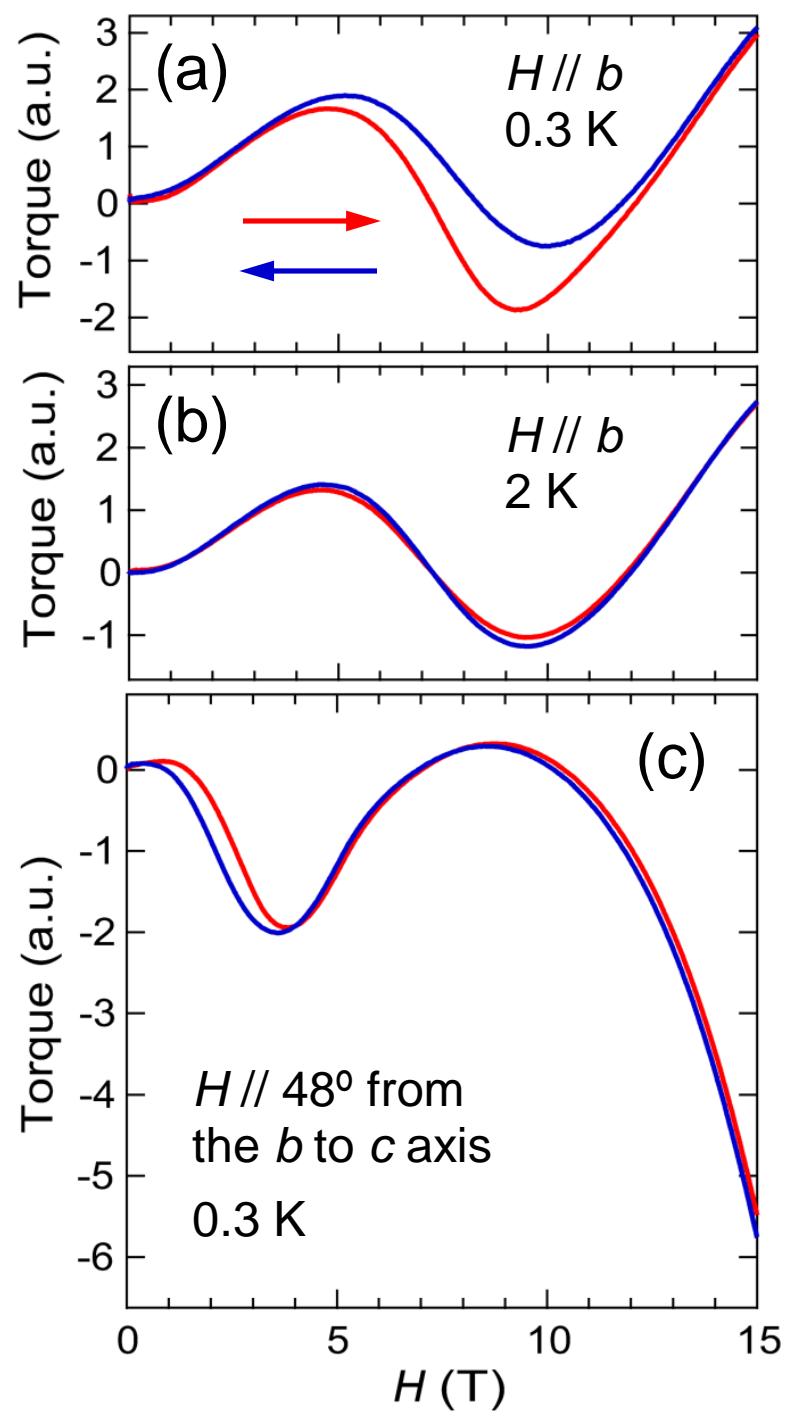

Figure S17. Hysteresis of the magnetic torque of the $\mathrm{FeBr}_{3} \mathrm{Cl}$ salt. Red and blue curves indicate up and down sweep, respectively. (a) Torque at $0.3 \mathrm{~K}$ under the field along the $b$ axis. (b) Torque at $2 \mathrm{~K}$ under the field along the $b$ axis. (c) Torque at $0.3 \mathrm{~K}$ under the field along $48^{\circ}$ from the $b$ to $c$ axis. The $\mathrm{FeBr}_{3} \mathrm{Cl}$ salt has an easy axis in between the $b$ and $c$ axes (ca. $45^{\circ}$ ) from the susceptibility anisotropy (Figure 4e). Therefore, Figures (a) and (c) indicate large hysteresis around the AF boundary and spin-flop field, respectively. 

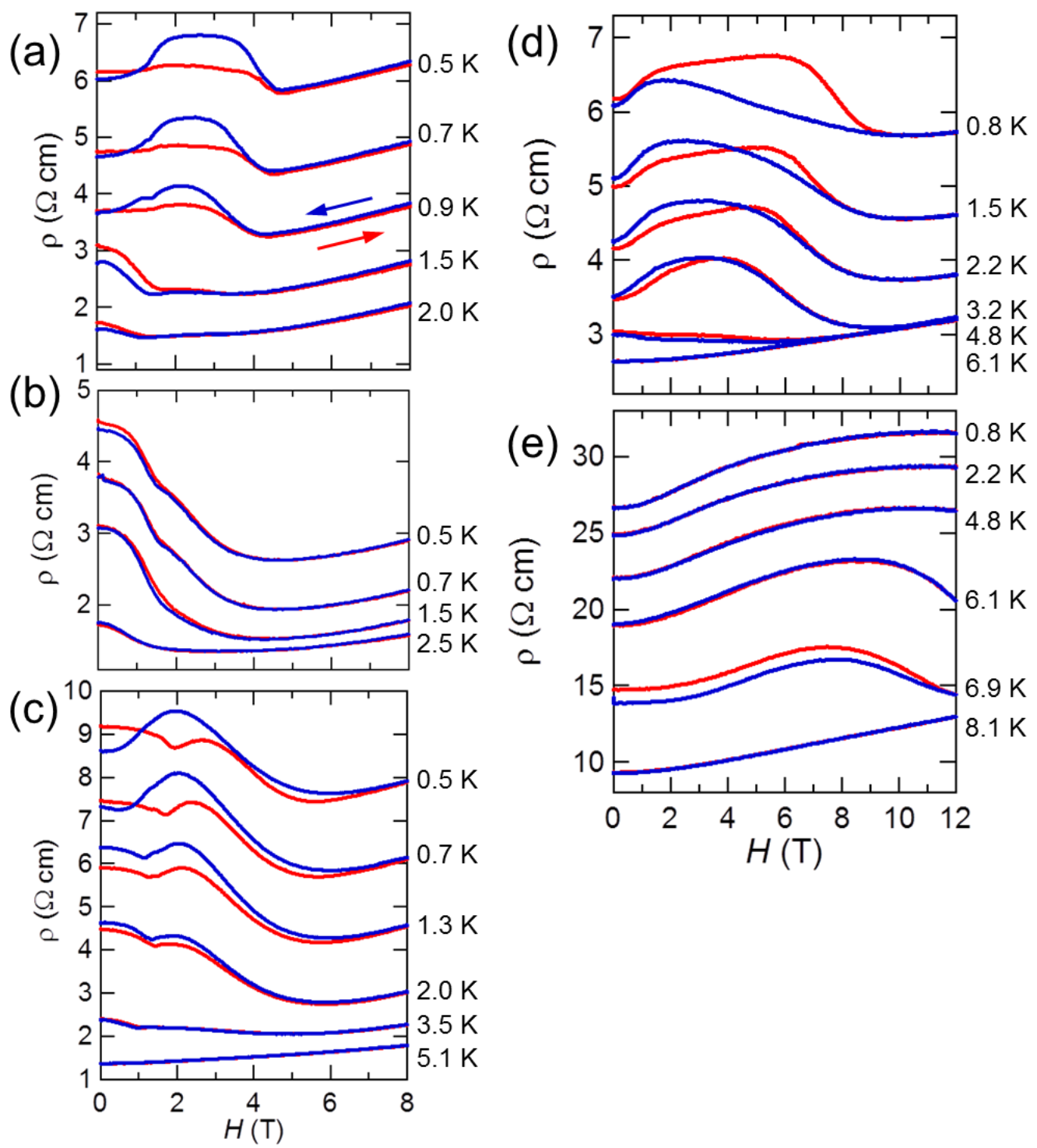

Figure S18. Up- and down-sweep magnetoresistance hysteresis of $\mathrm{FeCl}_{4}$ (a), $\mathrm{FeBrCl}_{3}$ (b), $\mathrm{FeBr}_{2} \mathrm{Cl}_{2}(\mathrm{c}), \mathrm{FeBr} 3 \mathrm{Cl}$ (d), and $\mathrm{FeBr}_{4}$ salts (e) at various temperatures with the magnetic fields along the $b$ axis. Red and blue curves are for up and down sweeps, respectively. Some data are shifted for clarity. 


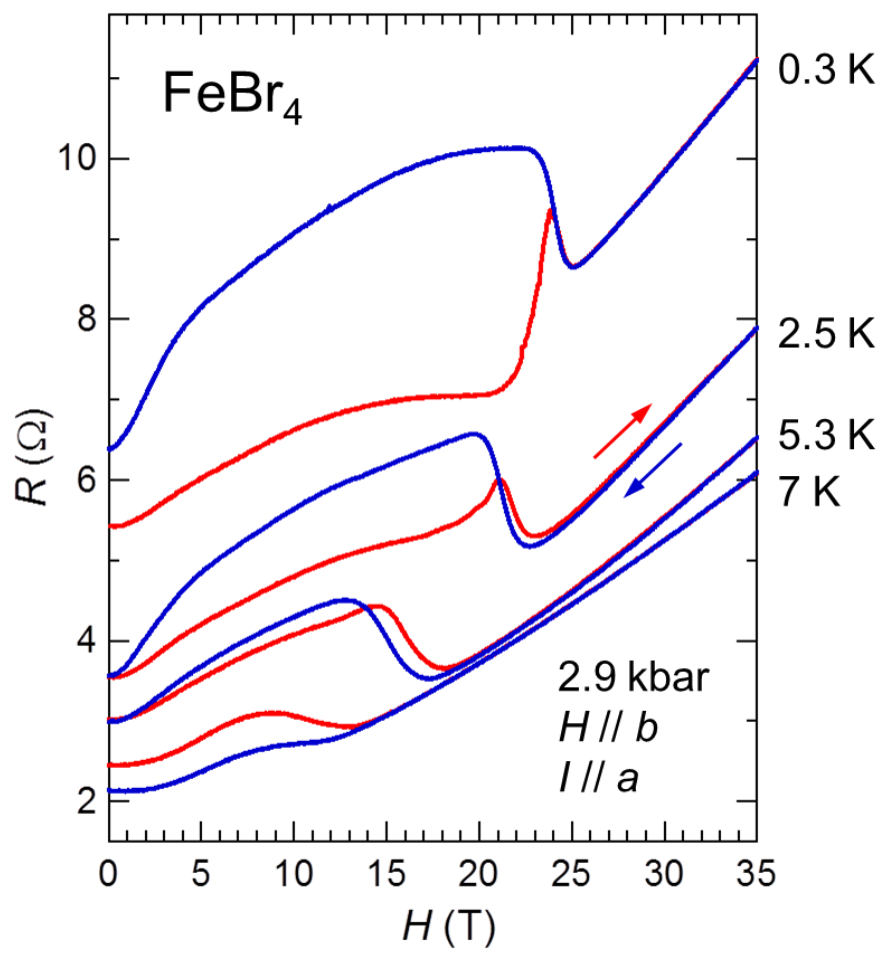

Figure S19. Up- and down-sweep magnetoresistance hysteresis of $\mathrm{FeBr}_{4}$ salts under the pressure of 2.9 kbar up to 35 $\mathrm{T}^{\mathrm{S} 12}$ The directions of magnetic field and current are the $b$ and $a$ axes, respectively. Red and blue curves are for up and down sweeps, respectively. Some data are shifted for clarity. 


\section{Reference}

[S1] Imakubo, T.; Shirahata, T. $\mathrm{CSe}_{2}$-free synthesis of [1,3]diselenole-2-thione and its application to syntheses of iodinated tetraselenafulvalenes (TSeFs). Chem. Commun. 2003, 1940-1941.

[S2] Kawaguchi, G.; Maesato, M.; Komatsu, T.; Kitagawa, H.; Imakubo, T.; Kiswandhi, A.; Graf, D.; Brooks, J. S. Unconventional Magnetic and Resistive Hysteresis in an Iodine-Bonded Molecular Conductor. Angew. Chem. Int. Ed. 2015, 54, 10169-10172.

[S3] Shirahata, T.; Kibune, M.; Maesato, M.; Kawashima, T.; Saito, G.; Imakubo, T. New organic conductors based on dibromo- and diiodo-TSeFs with magnetic and non-magnetic $\mathrm{MX}_{4}$ counter anions $(\mathrm{M}=\mathrm{Fe}, \mathrm{Ga} ; \mathrm{X}=\mathrm{Cl}, \mathrm{Br})$. J. Mater. Chem. 2006, 16, 3381-3390.

[S4] Bondi, A. van der Waals Volumes and Radii. J. Phys. Chem. 1968, 68, 441-451.

[S5] Perdew, J. P.; Burke, K.; Ernzerhof, M. Generalized Gradient Approximation Made Simple. Phys. Rev. Lett. 1996, 77, 3865-3868.

[S6] Clark, S. J.; Segall, M. D.; Pickard, C. J.; Hasnip, P. J.; Probert, M. J.; Refson, K.; Payne, M. C. First principles methods using CASTEP. Zeitschrift für Kristallographie 2005, 220, 567-570.

[S7] Vanderbilt, D. Soft self-consistent pseudopotentials in a generalized eigenvalue formalism. Phys. Rev. B 1990, 41, $7892-7895$.

[S8] Mori, T.; Kobayashi, A.; Sasaki, Y.; Kobayashi, H.; Saito, G.; Inokuchi, H. The Intermolecular Interaction of Tetrathiafulvalene and Bis(ethylenedithio)tetrathiafulvalene in Organic Metals. Calculation of Orbital Overlaps and Models of Energy-band Structures. Bull. Chem. Soc. Jpn. 1984, 57, 627-633.

[S9] To be reported elsewhere.

[S10] Maesato, M.; Kawashima, T.; Furushima, Y.; Saito, G.; Kitagawa, H.; Shirahata, T.; Kibune M.; Imakubo, T. Spin-Flop Switching and Memory in a Molecular Conductor. J. Am. Chem. Soc. 2012, 134, 17452-17455.

[S11] Kawaguchi, G.; Maesato, M.; Komatsu, T.; Imakubo, T.; Kitagawa, H. Interplay between spin-density wave and $3 d$ local moments with random exchange in a molecular conductor. Phys. Rev. B 2016, 93, 075124.

[S12] Maesato, M.; Furushima, Y.; Saito, G.; Kitagawa, H.; Imakubo, T.; Kiswandhi, A.; Graf, D.; Brooks, J. S. SpinCharge Coupling in the Molecular Conductor (DIETSe) ${ }_{2} \mathrm{FeBr}_{4}$. J. Phys. Soc. Jpn. 2013, 82, 043704. 